\section{PENGATURAN INTERNASIONAL TENTANG PENCEGAHAN PERDAGANGAN HEWAN DAN TUMBUHAN TERANCAM PUNAH (CITES) DAN KAITANNYA DENGAN PERLINDUNGAN SUMBER DAYA ALAM HAYATI DAN EKOSISTEMNYA DI INDONESIA ${ }^{1}$ \\ Oleh : Offel M. Panawar ${ }^{2}$ \\ Cornelis Dj. Massie ${ }^{3}$ \\ Thor Bangsaradja Sinaga ${ }^{4}$}

\begin{abstract}
ABSTRAK
Tujuan dilakukannya peneltian ini adalah untuk mengetahui bagaimana Pengaturan Internasional tentang Perdagangan Hewan dan Tumbuhan terancam punah menurut Konvensi Internasional CITES dan bagaimana peranan Hukum Nasional Indonesia dalam mencegah Perdagangan Hewan dan Tumbuhan terancam punah di tinjau dari Undang-undang No. 5 tahun 1990 tentang Konservasi Sumber Daya Alam Hayati dan Ekosistemnya. Dengan menggunakan metode peneltian yuridis normatif, disimpulkan: 1. Pengaturan internasional tentang perdagangan satwa liar dan tumbuhan terancam punah menurut konvensi CITES bertujuan untuk melindungi satwa liar dan tumbuhan dari perdagangan internasional, setiap Negara berdasarkan piagam PBB dan prinsip-prinsip hukum internasional, diakui memiliki kedaulatan penuh untuk memanfaatkan sumber daya alam sesuai dengan kebijakan lingkungan dan pembangunan masing-masing dan juga berkewajiban menjaga kegiatan yang
\end{abstract} berlangsung di wilayahnya berada di bawah pengawasan dan tidak menimbulkan kerusakan lingkungan. 2. Undang-undang No. 5 Tahun 1990 menyebutkan tentang Konservasi Sumber Daya Alam Hayati dan Ekosistemnya. Undangundang ini dibentuk karena kesadaran akan pentingnya sumber daya alam hayati bagi kehidupan masyarakat Indonesia dan perlu di kelola dan di manfaatkan bagi kesejahteraan masyarakat Indonesia sendiri, untuk melindungi hal tersebut perlu di lakukan konservasi terhadap sumber daya alam. Konservasi bertujuan untuk melindungi spesies-spesies yang dimiliki Indonesia, satwa liar dan

\footnotetext{
${ }^{1}$ Artikel Skripsi

${ }^{2}$ Mahasiswa pada Fakultas Hukum Unsrat, NIM.

${ }^{3}$ Fakultas Hukum Unsrat, Doktor IImu Hukum

${ }^{4}$ Fakultas Hukum Unsrat, Magister Ilmu Hukum
}

tumbuhan langkah merupakan bagian dari sumber daya alam sehingga kelestariannya perlu dijaga agar tidak punah dan tidak mengganggu keseimbangan ekosistem.

Kata kunci: Pengaturan Internasional, Pencegahan, Perdagangan Hewan dan Tumbuhan Terancam Punah (CITES), Perlindungan Sumber Daya Alam Hayati dan Ekositemnya

\section{PENDAHULUAN}

\section{A. Latar Belakang}

Indonesia juga menjadi habitat bagi satwasatwa endemik atau satwa yang hanya ditemukan di Indonesia saja. Keberadaan satwa endemik ini sangat penting, dikarenakan jika satwa tersebut punah, maka sudah bisa di pastikan pula bahwa tidak ada lagi satwa tersebut yang tersisa di dunia. Meskipun kaya akan satwa, namun Indonesia dikenal juga sebagai Negara yang memiliki daftar panjang tentang satwa liar yang terancam punah. Semua hal tersebut disebabkan oleh kurangnya kesadaran masyarakat akan pentingnya kelestarian satwa-satwa tersebut, dan maraknya penjualan satwa langka.

Indonesia menyimpan banyak keanekaragaman jenis satwa liar, namun juga merupakan salah satu Negara yang mempunyai laju kepunahan jenis satwa yang cukup tinggi. Daftar panjang tentang satwa liar yang terancam punah tersebut dapat dilihat dari sulitnya untuk melihat beberapa jenis satwa liar di habitat asliny. Satwa-satwa liar tersebut diantaranya yang sudah jarang ditemui di tempat aslinya, seperti harimau sumatera, badak bercula satu, anoa, burung cendrawasi, gajah sumatera, harimau jawa, dan masih banyak lagi satwa-satwa yang hidup di daratan, perairan, dan di udarah yang terancam punah. Saat ini diperkirakan jumlah jenis satwa liar yang terancam punah terdiri dari 147 jenis mamalia, 114 jenis ungags, 28 jenis reptil, 91 jenis ikan, dan 28 jenis invertebrata ${ }^{5}$.

Satwa adalah bagian dan sumber daya alam yang tidak ternilai harganya sehingga kelestariannya perlu dijaga melalui upaya meminimalisir perdagangan hewan ilegal dan perburuan satwa langka. Berdasarkan hal tersebut dan sebagai pelaksanaan undang-

\footnotetext{
${ }^{5}$ Website profauna indonesia.co.id. Slamet Khoiri. Satwa Liar Indonesia.
} 
undang Nomor 5 tahun 1990 tentang Konservasi Sumber Daya Alam Hayati dan Ekosistemnya, dipandang perlu untuk menetapkan peraturan tentang perdagangan jenis tumbuhan dan satwa. ${ }^{6}$

Hal ini menjadi acuan pada analisis hukum nasional Indonesia dalam undang-undang nomor 5 tahun 1990 tentang konservasi keanekaragaman hayati dan ekosistemnya, yang menjadi pendukung konvensi CITES yang melalui pasal 1 Undang-undang nomor 5 tahun 1990 melalui garis besarnya menjelaskan bahwa Sumber Daya Alam Hayati pengelolaan dan pemanfaatannya dilakukan secara bijaksana.

Sesuai dengan latar belakang di atas, hal tersebut mendorong penulis untuk menuangkan karya tulis dalam bentuk skripsi dengan judul "Pengaturan Internasional Tentang Pencegahan Perdagangan Hewan Dan Tumbuhan Terancam Punah (Cites) 1973 Dan Kaitannya Dengan Perlindungan Sumber Daya Alam Hayati Dan Ekosistem Di Indonesia".

\section{B. Rumusan Masalah}

1. Bagaimana Pengaturan Internasional tentang Perdagangan Hewan dan Tumbuhan terancam punah menurut Konvensi Internasional CITES?

2. Bagaimana peranan Hukum Nasional Indonesia dalam mencegah Perdagangan Hewan dan Tumbuhan terancam punah di tinjau dari Undang-undang No. 5 tahun 1990 tentang Konservasi Sumber Daya Alam Hayati dan Ekosistemnya?

\section{Metode Penelitian}

Metode penelitian yang digunakan dalam skripsi ini yaitu metode penelitian keperpustakaan (Library Research) yang dilakukan dengan membaca serta mempelajari sumber yang tertulis, kemudian diperoleh melalui buku-buku serta Perundang-undangan serta bahan tertulis lainnya. Penelitian ini termasuk penelitian yang bersifat deskriptif analitis, yang artinya menggambarkan fakta berupa data sekunder (data yang sudah ada) yang terdiri dari bahan Hukum Primer (Perundang-undangan).

\footnotetext{
${ }^{6}$ Eprints.umpo.ac.id.
}

\section{PEMBAHASAN}

\section{A. Peranan CITES dalam Mencegah Perdagangan Hewan dan Tumbuhan Terancam Punah.}

Berdasarkan keinginan untuk memanfaatkan tumbuhan dan satwa secara berkelanjutan, Indonesia telah turut meratifikasi CITES melalui Keppres no. 43 tahun 1978. Harus diakui bahwa walaupum sudah diratifikasi dalam waktu yang cukup lama, tetapi peraturan CITES belum dapat diimplementasikan secara optimal untuk mendukung perdagangan tumbuhan dan satwa yang berkesinambungan. Peraturan CITES mulai dari keharusan memiliki peraturan di tingkat nasional, penentuan kuota, mekanisme control pengambilan tumbuhan dan satwa di alam hingga pengawasan lalu lintas perdagangannya masi belum terlaksana dengan baik. ${ }^{7}$

Berbagai penelitian dan pengkajian terhadap dampak kegiatan manusia telah digelar oleh berbagai badan atau kelompok ilmiah maupun badan-badan resmi, pada tingkat nasional dan internasional, yang akhirnya menghantar masyarakat internasional kepada suatu kesimpulan bahwa:

...in ou time man's capability to transform his surrounding, if used wisely, can bring to all people the benefits of development and the opportunity to enchange the quality of life. Wrongly or heedlessly spplied, the same power can do incalculable harm to human being and the human environment. We see sorund us growing evidence of man-made, harm in many regions of the earth; dangerous level of pollution in water, air, earth and living being; major and undersirrable disturbance to the ecological balance of the biosphere; destruction and depletion of irreplaceable resources; and gross deficince, harmful to the physical, mental and social health of man in the man-made environment, particularly in the living and working environment. ${ }^{8}$

Untuk menghindarkan kemungkinan buruk itu masyarakat internasional juga sampai kepada kesimpulan bahwa:

The protection and improvement of the human environment is a major issue which affects the well-being of people and economic

\footnotetext{
${ }^{7}$ Diakses dari https://www.wwf.or.id. Pelaksanaan CITES di Indonesia. WWF

${ }^{8}$ Declaration of The United Nation Conference on The Human Environment. Proclaims 3.
} 
development throughout the world; it is the urgent desire of the people of the whole world and the dury of all goverment ${ }^{9}$

... we must shape our actions throughout the world with more pudent care for their environmental consequences. Throught ignorance or indifference we can do massive and irreversible harm to the earthly environment on which our life and well-being depend ... man must use knowledge to build, in collaboration with nature, a better environment. To defend and inprove the human environment for present and future generation has become inperative goal of mankind a goal to be pursued together with, and in harmony with, the established and fundamental goals of peace and world-wide economic and social development. ${ }^{10}$

Setiap Negara, berdasarkan piagam PBB dan prinsip=prinsip hukum internasional, diakui memiliki kedaulatan penuh untuk memanfaatkan sumber daya alam mereka, sesuai dengan kebijakan bidang lingkungan dan pembangunan masing-masing dan juga berkewajiban menjaga agar kegiatan yang berlangsung di dalam wilayahnya atau berada dibawah pengawasannya tidak menimbulkan kerusakan lingkungan Negara lain atau wilayah di luar batas wilayah nasional Negara-negara. ${ }^{11}$

1. Ketentuan CITES Tentang Perdagangan Satwa Liar.

Sejauh ini CITES telah mendata dan mendaftarkan lebih dari 30.000 spesies $^{12}$, yang mencakup sekitar 5.000 spesies hewan dan 25.000 spesies tumbuhan. Sebagian dari jumlah spesies tersebut merupakan spesies yang hanya hidup di Indonesia (spesies endemik). Spesies-spesies tersebut diklasifikasikan ke dalam apendiks-apendiks berdasarkan jumlah populasi dan tingkat ancaman terhadap spesies itu sendiri dari kepunahan. ${ }^{13}$

Mekanisme penggolongan perlindungan berdasarkan Appendix CITES, spesies-spesies hewan dan tumbuhan yang berada dalam

\footnotetext{
${ }^{9}$ Ibid. Proclaim 2.

${ }^{10} \mathrm{lbid}$. Proclaim 5.

${ }^{11}$ Prinsip 2. Deklarasi Rio 1992

12 <http://www.cites.org/eng/disc/text.shtml>

${ }^{13}$ Convention on the International Trade of Endangered Species. 1973. Pasal II.
}

pengawasan CITES dikelompokan dalam tiga kelompok yang dinamakan Appendix I, Appendix II, dan Appendix III. Penetapan daftar spesies perkelompok (Appendix) ditentukan berdasarkan konvensi dalam konferensi para pihak(COP).

2. Sistem Perizinan Internasional

a. Permberian Izin Eksport dan Import CITES memiliki sebuah mekanisme perizinan yang harus dipenuhi oleh Negara anggotanya dalam melakukan eksport dan import terhadap suatu spesies tertentu yang termasuk di dalam daftar perlindungan CITES $^{14}$

a. Izin eksport dan import untuk spesies dalam apendiks I

Segala spesies yang tercantum di dalam apendiks ini pada prinsipnya tidak boleh diperdagangkan. Spesiesspesies yang tercantum di dalam apendiks pertama ini terancam oleh kepunahan akibat atau yang dapat diakibatkan oleh perdagangan ${ }^{15}$. Untuk spesies yang tercantum di dalam apendiks I tidak dapat diperdagangkan kecuali untuk keadaan laur biasa, dan izin untuk melakukan eksport harus dibuktikan melalui export permits yang dikeluarkan oleh management authority Negara pengeksport.

Menurut pasal III ayat 2, pihak pengeksport harus memenuhi syarat (hal ini berlaku juga Negara hendak melakukan eksport ulang / re-export):

1. Pihak otoritas Negara pengeksport telah memberikan nasehat bahwa eksport spesies tersebut tidak akan melukai spesimen yang akan dieksport.

2. Pihak otoritas manajemen meyakini spesies yang di peroleh bukanlah hasil dari penangkapan yang melanggar hukum perlindungan spesies liar.

3. Pada proses pengapalan, harus dibuktikan bahwa kepada pihak otoritas manajemen bahwa tidak

\footnotetext{
${ }^{14}$ Patricia Birne and Alan Boyle. "International Law and the Environment". Oxfort University Press. 2002. hlm. 459. ${ }^{15}$ CITES, Pasal II (1).
} 
aka nada resiko terjadinya luka pada spesimen tersebut.

4. Otoritas manajemen Negara pengeksport juga harus meyakini bahwa izin impor atas spesimen tersebut telah diberikan oleh otoritas Negara pengimpor.

Dalam kasus eksport ulang, nasuhat dari otoritas ilmiah tidak diperlukan. Import permit dapat dikeluarkan oleh management authority CITES apabila persyaratan yang di atur dalam pasal III ayat (3), yaitu:

1. Otoritas ilmiah Negara pengimpor telah menasehati bahwa impor dilakukan bukan untuk tujuan melukai spesimen tersebut;

2. Otoritas ilmiah Negara pengimpor telah yakin bahwa Negara penerima sudah siap memberikan tempat perlindungan dan perawatan;

3. Otoritas manajemen Negara pengimpor meyakini impor tersebut bukan untuk tujuan komersial.

b. Izin ekspor dan impor untuk spesies dalam apendiks II

Apendiks II meliputi spesies yang saat ini belum terancam oleh kepunahan, namun sangat rentan terhadap kepunahan a[abila perdagangan atas spesies ini tidak diregulasi dan dilakukan pencegahan. Dalam hal perizinan untuk melakukan ekspor dan impor ketentuan yang berlaku untuk spesies dalam apendiks II ini lebih ringa, yaitu hanya dengan memenuhi segala persyaratan pengeksport saja, namun tidak membutuhkan import permit.

c. Izin ekspor dan impor untuk spesies dalam apendiks III

Apendiks III merupakan kategori spesies yang dimasukan dalam daftar=daftar Negara anggota CITES, dimana para anggota merasa bahwa spesies tersebut perlu dilindungi dan dibutuhkan kerjasama internasional untuk melindunginya. Dalam persyaratan spesies apendiks III hanya membutuhkan export permit saja, dan tidak membutuhkan import permit.

b. Pengecualian Persyaratan.

Selain pengaturan di atas, terdapat pengecualian terhadap ketentuanketentuan perdagangan hewan yang termasuk di dalam apendiks I, II, dan III. Persyaratan yang harus dipenuhi menurut pasal VIII adalah: ${ }^{16}$

1. Spesimen terdapat di dalam teritori Negara peserta dan dalam keadaan transit, dan spesiemen berada dibawah pengawasan dinas pabean;

2. Ketentuan dalam pasal III, IV, dan V tidak berlaku terhadap spesimen yang memiliki akibat-akibat terhadap personal atau persoalan rumah tangga. Atas pengecualian ini, juga terdapat pengecualian, yaitu bahwa pengeculian tidak berlaku jika:

a. Dalam kasus spesimen dalam apendiks I, spesimen tersebut diperoleh oleh pemiliknya di luar Negara tempat kediamannya, dan diimpor ke dalam Negara tersebut.

b. Dalam kasus spesimen dikategorikan di dalam apendiks II:

i. Spesimen tersebut diperoleh oleh pemiliknya di luar Negara tempat kediamannya dan dalam suatu Negara dimana pemindahan dari alam bebas dilakukan;

ii. Spesimen tersebut diimpor ke dalam Negara kediaman pemiliknya;

iii. Negara dimana terjadi pemindahan dari alam bebas menuntut pengabulan export permit terlebih dahulu sebelum eksport terhadap spesimen itu dilakukan.

3. Perdagangan dilakukan sebelum spesies tersebut dimasukkan ke dalam salah satu apendiks CITES;

4. Spesimen yang merupakan hasil dari penangkaran juga dikecualikan, spesimen yang didapatkan dari hasil penangkaran hendaknya dianggap

\footnotetext{
${ }^{16}$ CITES Pasal 8.
} 
sebagai spesimen dari spesies yang berada di apendiks II;

5. Pengecualian juga berlaku jika otoritas manajemen Negara pengekspor meyakini bahwa setiap spesimen dari spesies tumbuhan dan satwa merupakan hasil penangkaran atau pengembangbiakan secara sengaja;

6. Spesimen sebagai bagian dari museum, ekspor untuk eksebisi. Sirkus, sepanjang didaftarkan pada otoritas manajemen Negara bersangkutan.

c. Lembaga Otoritas CITES.

\section{Management Authority}

Management Authoriry atau otoritas manajemen ditugaskan CITES untuk mengabulkan CITES Permits. Perkembangan dari otoritas manajemen di setiap Negara tidaklah sama. Pada umumnya suatu otoritas manajemen harus menentukan halhal berikut: ${ }^{17}$

1. Spesimen yang diperdagangkan tidak diperoleh melalui pelanggaran hukum nasional suatu Negara;

2. Spesimen hidup dari spesies harus dipersiapkan dan dikapalkan dalam cara yang diyakini tidak akan merugikan keselamatan spesimen tersebut;

3. Suatu import permit telah diberikan bagi spesimen dalam apendiks I sebelum export permit Negara pengekspor dikeluarkan;

4. Harus dipastikan impor spesimen dari apendiks I tidak dilakukan untuk tujuan komersial;

5. Sebelum export/import permit dikeluarkan, dipastikan otoritas manajemen telah mendapatkan nasihat otoritas ilmiah yang sama.

2. Scientific Authority

Otoritas ilmiah atau scientific authority memberikan nasehat kepada otoritas manajemen apakah perdagangan yang akan dilakukan melalui ekspor/impor dapat

\footnotetext{
${ }^{17}$ <http://www.cnie.org/nie/biodv-7.html>
}

membahayakan kehidupan suatu spesimen. Hal yang juga harus diyakini oleh otoritas ilmiah adalah apakah orang yang akan menerima spesimen akan dapat memelihara spesimen tersebut dengan baik.

\section{B. Peranan Hukum Nasional Terhadap Perdagangan Hewan dan Tumbuhan Terancam Punah Ditinjau dari Undang- Undang no 5 Tahun 1990.}

Dalam praktik Indonesia, sekalipun suatu perjanjian internasional telah diratifikasikan dengan undang-undang, masih dibutuhkanundang-undang lain untuk mengimplementasikannya pada domain hukum nasional. ${ }^{18}$

Di indonesia setidaknya terdapat beberapa peratran yang berkenan dengan pemanfaatan spesies-spesies di wilayah teritori Indonesia, maupun yang mengatur mengenai konservasi maupun perdagangan spesies yang terancam punah.

a. Keputusan Presiden Republik Indonesia No. 43 tahun 1978 tentang pengesahan Convention on International Trade in Endangered Species of Wild Flora and Fauna ( peraturan ini yang meratifikasi CITES kedalam dan merupakan inti dari peraturan pelaksanaan CITES di Indonesia.

b. Undang-undang Negara Republik Indonesia No. 5 tahun 1990 mengenai Konservasi Sumber Daya Alam dan Ekosistemnya.

c. Peraturan Pemerintah Republik Indonesia No. 7 tahun 1999 tentang pengawetan jenis Tumbuhan dan Satwa.

d. Peraturan Pemerintah Republik Indonesia No. 8 tahun 1999 tentang pemanfaatan jenis Tumbuhan dan Satwa.

e. Keputusan Menteri Kehutanan RI No 36/kpts-II/1996 tentang penunjukan Direktorat Jendral perlindungan Hutan dan Pelestarian Alam selaku pemegang kewenangan manajemen otoritas CITES.

f. Keputusan Menteri Kehutanan RI No. 62/kpts-II/1998 tentang Tata Usaha Peredaran Tumbuhan dan Satwa liar.

18 DR. iur. Damos Dumoli Agusman, SH., MA. 2017 "HUKUM PERJANJIAN INTERNASIONAL Kajian Teori dan Praktik Indonesia" Refika Aditama. Bandung. hIm. 105. 
g. Keputusan Menteri Kehutanan dan Perkebunan No. 104/kpts-II/2000 tentang Tata Cara Mengambil Tumbuhan Liar dan Menagkap Satwa Liar.

\section{a. UU No. 5 Tahun 1990 tentang Konservasi}

\section{Sumber Daya Alam Hayati dan} Ekosistemnya.

Undang-undang ini merupakan undangundang ini dibentuk karena kesadaran akan pentingnya keanekaragaman hayati bagi kehidupan masyarakat Indonesia, dan keanekaragaman hayati itu perlu dikelola dan dimanfaatkan bagi kesejahteraan masyarakat Indonesia sendiri, ${ }^{19}$ Untuk melindungi keanekaragaman hayati tersebut perlu dilakukan konservasi terhadap sumber daya alam hayati yang dimiliki Indonesia. Konservasi itu sendiri ditujukan untuk melindungi spesiesspesies yang dimiliki Indonesia dan mengelola pemanfaatannya secara berkelanjutan bagi kepentingan masyarakat. $^{20}$

Dalam undang-undang ini pun dinyatakan bahwa konservasi merupakan tanggung jawab dari Negara ( pasal 4 ), dan dapat dilakukan dengan kegiatan ( pasal 5 ):

i) Perlindungan sistem penyangga kehidupan;

ii) Pengawetan keanekaragaman jenis tumbuhan dan satwa beserta ekosistemnya;

iii) Pemanfaatan secara lestari sumber daya alam hayati dan ekosistemnya.

Dengan memelihara proses ekologi tersebut maka kesejahteraan masyarakat Indonesia dapat ditingkatkan karena adanya pemanfaatan yang menguntungkan baik bagi masyarakat dan ekosistem itu sendiri. Karena itulah perlu dibentuk sebuah wilayah perlindungan bagi keanekaragaman hayati tersebut, pola pembinaan wilayah perlindungan, dan pengaturan mengenai pemanfaatan dari keanekaragaman hayati tersebut. $^{21}$

Dalam Undang-undang ini pun telah dikenal konservasi in-situ dan ex-situ sebagaimana dijabarkan dalam pasal $13(1)$ yang mengatakan bahwa:

\footnotetext{
19 Indonesia UU No. 5 tahun 1990 tentang Konservasi Sumber Daya Alam Hayati dan Ekosistemnya. Pertimbangan huruf a.

${ }^{20}$ Indonesia Loc. Cit. pertimbangan huruf $\mathrm{d}$.

21 Indonesia. Loc. Cit. Pasal 7 dan 8.
}

“(1) Pengawetan jenis tumbuhan dan satwa dilaksanakan di dalam dan di luar kawasan suaka alam." 22

Dengan kata lain dapat dikatakan bahwa konservasi dapat dilakukan baik di dalam habitat dari spesies tersebut ( in-situ ) maupun di luar habitatnya ( ex-situ ).

Prinsip sustainable use juga telah dikenal di sini, dimana pemanfaatan tersebut pada dasarnya tidak boleh mengakibatkan kerusakan terhadap keanekaragaman hayati ( baik tumbuhan maupun satwa ) tersebut dengan memperhatikan potensi, daya dukung dan keanekaragaman jenis tumbuhan atau satwa tersebut ( pasal 26-28) pemanfaatan itu pun bisa dilakukan dalam bentuk (pasal36):
a. Pengkajian, penelitian pengembangan;
b. Penangkaran;
c. Perburuan;
d. Perdagangan;
e. Peragaan;
f. Pertukaran;
g. Budidaya tanaman obat-obatan;
h. Pemeliharaan untuk kesenangan. ${ }^{23}$

dan

\section{b. Perbuatan Yang Termasuk Tindak Pidana Terhadap Tumbuhan dan Satwa Liar Yang Dilindungi menurut Undang-undang Nomor 5 Tahun 1990.}

Rumusan mengenai perbuatan pidana yang dilarang dalam tindak pidana perdagangan Tumbuhan dan Satwa liar yang dilindungi pada dasarnya mengacu kepada peraturan perundang-undangan yang mengatur mengenai upaya-upaya untuk pelestarian dan perlindungan Tumbuhan dan Satwa liar yang dilindungi yaitu Undang-undang Nomor 5 Tahun 1990 tentang Konservasi Sumber Daya Alam Hayati dan Ekosistemnya.

\section{PENUTUP}

\section{A. Kesimpulan}

1. Pengaturan internasional tentang perdagangan satwa liar dan tumbuhan terancam punah menurut konvensi CITES bertujuan untuk melindungi satwa liar dan tumbuhan dari perdagangan

\footnotetext{
${ }^{22}$ UU No.5 tahun 1990 tentang Konservasi sumber Daya Alam Hayati dan Ekosistemnya. Pasal 13 ayat 1.

${ }^{23}$ UU No. 5 tahun 1990 tentang Konsevasi Sumber Daya Alam Hayati dan Ekosistemnya Pasal 36.
} 
internasional, setiap Negara berdasarkan piagam PBB dan prinsip-prinsip hukum internasional, diakui memiliki kedaulatan penuh untuk memanfaatkan sumber daya alam sesuai dengan kebijakan lingkungan dan pembangunan masingmasing dan juga berkewajiban menjaga kegiatan yang berlangsung di wilayahnya berada di bawah pengawasan dan tidak menimbulkan kerusakan lingkungan.

2. Undang-undang No. 5 Tahun 1990 menyebutkan tentang Konservasi Sumber Daya Alam Hayati dan Ekosistemnya. Undang-undang ini dibentuk karena kesadaran akan pentingnya sumber daya alam hayati bagi kehidupan masyarakat Indonesia dan perlu di kelola dan di manfaatkan bagi kesejahteraan masyarakat Indonesia sendiri, untuk melindungi hal tersebut perlu di lakukan konservasi terhadap sumber daya alam. Konservasi bertujuan untuk melindungi spesies-spesies yang dimiliki Indonesia, satwa liar dan tumbuhan langkah merupakan bagian dari sumber daya alam sehingga kelestariannya perlu dijaga agar tidak punah dan tidak mengganggu keseimbangan ekosistem.

\section{B. Saran}

1. Konvensi internasional yang merupakan bagian dari pengaturan internasional mempunyai kekuatan hukum yang kuat sehingga dapat diperhatikan melalui CITES diharapkan seluruh kegiatan perdagangan illegal eksport maupun import satwa liar dan tumbuhan dapat di tindak secara praktis .

2. sebagai salah satu sumber hukum nasional Undang-undang No. 5 tahun 1990 tentang Konservasi Sumber Daya Alam Hayati dan Ekosistemnya dapat di perkuat kembali dalam mencegah dan menangani perdagangan satwa liar dan tumbuhan di Indonesia.

\section{DAFTAR PUSTAKA}

Anwar, Chairul. 1988. Hukum Internasional Pengantar Hukum Bangsa-Bangsa. Jakarta: Djambatan
Atmasasmita, Romli. 2000. Pengantar Hukum Pidana Internasional. Bandung: PT. Refika Aditama.

Agusman, lur. Damos Dumoli. 2017 "HUKUM PERJANJIAN INTERNASIONAL Kajian Teori dan Praktik Indonesia". Bandung: Refika Aditama.

Birne, Patricia dan Alan Boyle. 2002. International Law and the Environment. London: Oxford University Press.

Broad, S., Mulliken T. and Roe D. 2003. "The Nature and Exient of Legal and llegal Trade in Wildlife".

Garner, Bryan A. 2004. Black's Law Dictionary (Eighth Edition). Thomson West. U.S.A.

Grieser, Johns. A. 2004. "Pangolins for Television: A case study of the commercialization of vietnam's wildlife and the impact of a development project". Stockholm: Orgut Consulting $A B$.

Gulland, Milner. E. J. and Mace. R. 1998. "Conservation of Biological Resources". London: Blackwell Science Oxford.

Hardjasoemantri, Koesndi. 2012. Hukum Tata Lingkunga. Yogyakarta: Gadjah Mada Unuversity Press.

Hiariej, Eddy O.S. Prinsip-prinsip Hukum Pidana. Yogyaarta. Cahya Arma.

Henderson, Conway W. 2010. Understanding International Law. Ho Printing Singapore Pte Ltd.

Huala, Adolf. Hukum Penyelesaian Sengketa Internasonal. Sinar Grafika.

Kansil, Christine S. T. 2013. Pokok-pokok Pengetahuan Hukum Dagang Indonesia Edisi 2. Jakarta: Sinar Grafika.

Kusumaatmadja, Mochtar. 1997. Pengantar Hukum Internasional. Jakarta: Binacipta.

Laden Marpaung. 1995. Tindak Pidana Terhadap Hasil Hutan dan Satwa. Surabaya: Erlangga Press.

Lemanseto, Haryo. 2015. "Jaga Alam, Lingkungan Flora dan Fauna Indonesia" Majalah Warta Bea Cukai Nomor 01331/SK/DIRDJEN-PG/SIT/1972. 20 Juni 1970.

Liljeblad, Jonathan. 2014. The Convention on International Trade of Endangered Species. New South Wales. 
Mauna, Boer. 2005. Hukum Internasional. Pengertian. Peranan dan Fungsi dalam Era Dinamika Global. Bandung: Alumni.

Mertokusumo, Sudikho. 2003. Mengenal Hukum (sebuah pengantar). Yogyakarta: Liberty.

Muhamad Iqbal. 2014. "Tinjauan Yuridis Terhadap Kepemilikan dan Penjualan Satwa Langka Tanpa Izin di Indonesia". Jurnal Fakultas Hukum Universitas Mulawarman. Kalimantan Timur.

Neumann. R. P. and Hirsch. E. 2000. "Commercialisation of non-timber forest product: review and analysis of research". Bogor: Center for International Forestry Research.

Parthiana, I Wayan. 2002. Hukum Perjanjian Internasional. Bagian 1. Bandung: Mandar maju.

Pata'dungan, Roby Yolis. 2013. “Implementasi CITES (Convention on International Trade in Endangered Species of Wild Fauna and Flora) dalam upaya konservasi penyu di Indonesia". Ejournal Fakultas IImu Sosial dan Politik Universitas Mulawarman. Kalimantan Timur.

Saleh, Chairul. Hilaluddin, Imelda. Hanif, Fatni. 2007. "Lokakarya mengenai Penegakan Hukum Perdagangan Ilegal Hidupan Liar".

Sefriant. 2011. Suatu Pengantar Hukum Internasional. Jakarta: Rajawali Press.

Soeharto, Tony dan Mardiastuti, Ani. 2003. Pelaksanaan Konvensi Cites di Indonesia. Jakarta: Japan international cooperation agency.

Sukanda, Husin. 2006. "Pengaturan Perlindungan Keanekaragaman Hayati dalam Lingkungan Internasional edisi XV". Jurnal Hukum Universitas Andalas. Sumatera Utara. .

Suryokusumo, Sumaryo. 2008. Hukum Perjanjian Internasional. Jakarta: Tata Nusa.

TRAFFIC, 2008 "What's Driving the Wildlife Trade? A review of Expert Opinion on Economic and Social Drivers of the Wildlife Trade and Trade Control Efforts in Cambodia, Indonesia, Lao PDR and Vietnam". (East Asia and Pacific Region Sustainable Development Discussion
Papers. East Asia and Pacific Region Sustainable Development Department. Washington DC: World Bank.

Tumpal, Rumpes. 2000. Kamus Lengkap Perdagangan Internasional Cetakan Pertama. Jakarta: PT Gramedia Pustaka Utama.

\section{Peraturan Perundang-Undangan}

Convention on Biological Diversity. 1992.

Convention on International Trade in Endangered of Species Wild Fauna and Flora(CITES).

Declaration of The United Nation Conference on The Human Environment.

Deklarasi Rio 1992.

Konvensi London tahun 1900.

Konvensi Wina tahun 1969.

Keputusan Presiden Republik Indonesia Nomor 43 tahun 1978.

UU No. 5 tahun 1990 tentang Konservasi Sumber Daya Alam Hayati dan Ekosistemnya.

Undang-undang nomor 24 tahun 2000 tentang perjanjian internasional. 